\title{
Effect of dietary coenzyme Q10 supplementation on serum and bone minerals and leg weakness mortality in broilers
}

\author{
M. Gopi, M. R. Purushothaman and D. Chandrasekaran \\ Veterinary College and Research Institute, \\ Tamil Nadu Veterinary and Animal Sciences University, Namakkal, Tamil Nadu - 637 002, India \\ Corresponding author: M. Gopi, email: gopsgopi72@gmail.com \\ Received: 22-03-2014, Revised: 14-04-2014, Accepted: 19-04-2014, Published online: 24-05-2014
}

doi: $10.14202 /$ vetworld.2014.347-350

How to cite this article: Gopi M, Purushothaman MR and Chandrasekaran D (2014) Effect of dietary coenzyme Q10 supplementation on serum and bone minerals and leg weakness mortality in broilers, Veterinary World 7(5): 347-350.

\begin{abstract}
Aim: This work was carried out to study the effect of coenzyme Q10 supplementation on serum calcium and phosphorus levels, tibial bone weight, bone ash, bone calcium and phosphorus levels and mortality of birds due to leg weakness when the broilers were maintained under high environmental temperature.

Materials and Methods: The trial was carried out on 216 Cobb400 broiler chicks and divided into four groups with nine replicates and each replicate consisting of six birds. The treatments include normal energy diet (NE) (as per breeder's specifications) (G1), high energy (HE) (NE plus $100 \mathrm{kcal} / \mathrm{kg}$ ) diet without CoQ10 supplementation (G2), high energy diet supplemented with CoQ10 at $20 \mathrm{mg} / \mathrm{kg}$ (G3) and high energy diet supplemented with CoQ10 at $40 \mathrm{mg} / \mathrm{kg}$ (G4). The experiment was carried out when the temperature humidity index (THI) ranged from 33.05 to $38.65^{\circ} \mathrm{C}$ for a period of 42 days.

Results: The serum calcium and phosphorus levels in the G1, G2, G3 and G4 were 9.07 $\pm 0.22,8.48 \pm 0.10,8.30 \pm 0.10,8.32 \pm$ 0.12 and $4.90 \pm 0.20,4.06 \pm 0.32,3.96 \pm 0.17,4.02 \pm 0.24$, respectively. The tibial bone weight $(\mathrm{g})$ was $21.58 \pm 1.32,17.92 \pm$ $1.90,18.67 \pm 1.30$ and $17.42 \pm 1.18$; tibial bone Ash $(\%) 46.67 \pm 2.71,44.48 \pm 2.40,44.66 \pm 3.09$ and $44.62 \pm 1.74$; Bone calcium (\%) $33.57 \pm 0.2,31.27 \pm 0.55,31.50 \pm 0.45$ and $31.47 \pm 0.83$, bone phosphorus $(\%)$ was $11.86 \pm 0.16,10.38 \pm 0.11$, $10.68 \pm 0.08$ and $10.39 \pm 0.17$, respectively in G1, G2, G3 and G4 groups. The serum calcium and phosphorus levels were significantly higher $(\mathrm{P}<0.05)$ in $\mathrm{G} 1$ over the other three groups. The tibial bone weight was not altered by the energy level or the coenzyme Q10 supplementation. The tibial bone calcium and phosphorus levels were significantly higher in G1 than the other three groups.
\end{abstract}

Conclusion: The supplementation of coenzyme Q10 did not alter the serum and tibial bone calcium and phosphorus levels. The leg abnormality associated mortality was significantly decreased in G3 group when compared to the other two high energy groups.

Keywords: bone minerals, broilers, CoQ10, temperature humidity index, tibial bone ash.

\section{Introduction}

Bone mineral content was commonly used as an indicator of mineral adequacy diets of poultry [1]. The major minerals that form the inorganic matrix of bone are calcium and phosphorus [2]. The extent of bone mineralization affects bone strength [2] and poor mineralization leads to increased risk of fractures [3]. Skeletal abnormalities and architectural deterioration of bone tissue are common under hot climatic conditions because a high environmental temperature leads to more excretion of minerals like calcium, iron, zinc and lower retention rates of minerals like calcium, phosphorus, sodium, manganese, copper and zinc resulting in decreased bone strength of broilers [4-7].

Heat stress has deleterious effects on the skeletal system by decreasing length and widths of tibia, and by promoting mineralization which in turn reduces bone strength [8]. Rapid growth followed by high nutrient intake with energy high diet alone can cause severe

Copyright: The authors. This article is an open access article licensed under the terms of the Creative Commons Attribution License (http://creativecommons.org/licenses/by/2.0) which permits unrestricted use, distribution and reproduction in any medium, provided the work is properly cited. lameness, bone defects, and deformity [9]. Tibia ash and bone - calcium and phosphorus per cent in broilers were lower in higher metabolizable energy (ME) fed birds than the low ME diet fed groups [10]. Thus for optimal broiler production in the hot environmental conditions, adequate and appropriate management system is required that can reduce the effects of heat stress on growth as well as mineral excretion to a minimum extent. Calcium absorption is increased by CoQ10 supplementation [11, 12]. The dietary antioxidant supplementation decreased the mineral excretion in hot climatic condition in broilers [4]. CoQ10 is a lipophilic antioxidant and its supplement reduces the oxidative stress and increased the enzymatic antioxidant activity [13].

Hence, the trial was carried out with Coenzyme Q10 which provides the antioxidant property and promotes calcium retention in the system, and may alleviate the adverse effects of heat stress on bone mineralisation.

\section{Materials and Methods}

Ethical approval: The experiment was carried out 
Table-1: Ingredients and nutrients composition (\% DM) of broiler pre starter, starter and finisher diets

\begin{tabular}{|c|c|c|c|c|c|c|}
\hline \multirow[t]{2}{*}{ Ingredients (\%) } & \multicolumn{2}{|c|}{ Pre-starter } & \multicolumn{2}{|c|}{ Starter } & \multicolumn{2}{|c|}{ Finisher } \\
\hline & NE & $\mathrm{HE}$ & $\mathrm{NE}$ & HE & $\mathrm{NE}$ & HE \\
\hline Maize & 54.2 & 49.88 & 53.9 & 50.5 & 57.22 & 52.79 \\
\hline DORB & 0.07 & 0.035 & 0.36 & 1.1 & 0.0 & 0.89 \\
\hline SOYA & 39.58 & 41.78 & 37.5 & 37.9 & 32.58 & 34.26 \\
\hline Rice bran Oil & 2.12 & 4.3 & 4.24 & 6.3 & 5.86 & 8.0 \\
\hline Calcite & 1.54 & 1.53 & 1.52 & 1.5 & 1.73 & 1.48 \\
\hline DCP & 0.9 & 0.88 & 0.95 & 0.94 & 1.10 & 1.05 \\
\hline Salt & 0.180 & 0.181 & 0.181 & 0.182 & 0.184 & 0.184 \\
\hline Lysine & 0.298 & 0.302 & 0.150 & 0.189 & 0.167 & 0.168 \\
\hline Methionine & 0.304 & 0.319 & 0.283 & 0.315 & 0.272 & 0.293 \\
\hline Threonine & 0.00 & 0.035 & 0.00 & 0.00 & 0.018 & 0.018 \\
\hline \multicolumn{7}{|l|}{ Nutrients (\%) } \\
\hline Crude protein & 22.65 & 23.30 & 21.65 & 21.75 & 19.70 & 20.21 \\
\hline Metabolisable Energy $(\mathrm{Kcal} / \mathrm{kg})^{*}$ & 3000 & 3100 & 3125 & 3225 & 3250 & 3350 \\
\hline Calcium & 0.96 & 0.96 & 0.95 & 0.95 & 0.90 & 0.90 \\
\hline Available phosphorus* & 0.45 & 0.45 & 0.47 & 0.47 & 0.46 & 0.46 \\
\hline 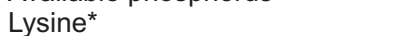 & 1.42 & 1.47 & 1.25 & 1.29 & 1.14 & 1.18 \\
\hline Methionine* & 0.62 & 0.64 & 0.59 & 0.61 & 0.55 & 0.57 \\
\hline
\end{tabular}

Mineral mixture addition at $0.1 \%$ supplied (in $\mathrm{mg}$ ) manganese -91 , zinc -91 , iron-85, iodine -1.82 , copper -30.24 and cobalt - 0.365. Vitamin premix added at $0.5 \mathrm{~g}$ per $\mathrm{kg}$ feed supplied vitamin A-16500 IU, B2-13 mg, D3-3200 IU and vitamin K-2 mg, thiamine $-5 \mathrm{mg}$, pyridoxine $-8 \mathrm{mg}$, Niacin-320 mg, cyanocobalamine $-0.05 \mathrm{mg}$, vitamin E- $95 \mathrm{mg}$, calcium D pantothenate $27.5 \mathrm{mg}$ and folic acid $-14 \mathrm{mg}$, calcium $-30.1 \mathrm{mg}$. Coccidiostat added at $0.5 \mathrm{~g}$ per kg feed supplied $125 \mathrm{mg}$ of Di-nitro-orthotoluamide. Antibiotic ( $10 \%$ Oxy tetracycline) $0.5 \mathrm{~g}$ was added per $\mathrm{kg}$ of feed.

* Calculated values.

Table-2: Ingredients and nutrients composition (\% DM) of broiler pre starter, starter and finisher diets

\begin{tabular}{ll}
\hline Observation & Score \\
\hline Leg appeared completely normal & ONE \\
Slight amount of swelling at the tibia - metatarsal joint & TWO \\
Marked degree of swelling of tibia - metatarsal joint & THREE \\
Swelling plus a slight amount of slipping of the Achilles tendon & FOUR \\
Swelling combined with marked slipping of tendon & FIVE \\
\hline
\end{tabular}

according to the National regulations on animal welfare and Institutional Animal Ethical Committee.

Experimental design: The broiler trail was conducted with 216-day old Cobb400 broiler chicks reared under standard managemental practices in the open sided broiler house. They were divided into four groups containing nine replicates of each consisting of six chicks and labelled as normal energy diet without coenzyme Q10 supplementation (G1), high energy diet without coenzyme Q10 supplementation (G2), high energy diet supplemented with coenzyme Q10 at 20 $\mathrm{mg} / \mathrm{kg}$ of diet (G3) and high energy diet supplemented with coenzyme Q10 at $40 \mathrm{mg} / \mathrm{kg}$ of diet (G4). The ingredients and nutrients composition (\% DM) of broiler pre starter, starter and finisher diets are presented in Table-1. The birds were reared for six weeks and gait and leg abnormalities were studied. The daily maximum and minimum temperature and relative humidity inside the shed were recorded and temperature humidity index was calculated as per Tao and Xin [14]. At the end of 42 days twelve birds per treatment (six males and six females) were sacrificed, blood was collected and allowed to clot and the serum was separated and both the right and left tibial bone was collected.

The collected tibial bone was weighed and preserved by defatted for the estimation of tibial bone ash, calcium and phosphorus. The tibial bones were boiled in water for 30 minutes to clean the adhering flesh and connective tissues, dried at $100^{\circ} \mathrm{C}$ for $24 \mathrm{~h}$, defatted with petroleum ether and ashed at $550^{\circ} \mathrm{C}$ for 3 hours. The percentage of tibia ash to dried tibial weight was calculated. The tibial bone calcium and phosphorus was estimated as per AOAC [15] and the levels were expressed in per cent. The degree of leg abnormality was measured by examining the hock joint. Each chick was assigned a value in the range from one to five depending upon degree of leg abnormality (Table-2) [16].

Statistical analysis: The statistical analysis was performed using the SPSS 20.0 software package (SAS, Cary, NC, USA). Results are presented as arithmetic mean \pm standard errors (SE).

\section{Results and Discussion}

The observation of serum calcium and phosphorus and tibial bone weight, percentage of tibial bone ash and tibial calcium and phosphorus (\%) are presented in Table-3. The serum calcium and phosphorus content in G1was significantly higher than other three high energy groups also reported by Riyazi et al. [17]. Papadimitriou et al. [11] reported that the calcium absorption was increased by CoQ10 supplementation by the mechanism of increasing the capacity of producing vitamin $\mathrm{D}_{3}$ in mitochondria of proximal tubules of kidney. But in our study the CoQ10 supplementation (G3 and G4) the calcium level was not altered. 
Table-3: Influence of Coenzyme Q10 at two levels on the tibial bone, production score, leg weakness and leg abnormality score of broilers

\begin{tabular}{|c|c|c|c|c|c|c|}
\hline Parameter & G1 & G2 & G3 & G4 & P-value & CD value \\
\hline \multicolumn{7}{|l|}{ Serum Minerals } \\
\hline Calcium & $9.07^{b} \pm 0.22$ & $8.48^{a} \pm 0.10$ & $8.30^{a} \pm 0.10$ & $8.32^{a} \pm 0.12$ & 0.001 & 0.41 \\
\hline $\begin{array}{l}\text { Phosphorus } \\
\text { Tibial bone analysis }\end{array}$ & $4.90^{b} \pm 0.20$ & $4.06^{a} \pm 0.32$ & $3.96^{a} \pm 0.17$ & $4.02^{a} \pm 0.24$ & 0.025 & 0.69 \\
\hline Tibial bone weight (g) & $21.58 \pm 1.32$ & $17.92 \pm 1.90$ & $18.67 \pm 1.30$ & $17.42 \pm 1.18$ & 0.19 & -- \\
\hline $\begin{array}{l}\text { Defatted tibial bone weight }(\mathrm{g}) \\
\text { Tibial bone Ash (\%) }\end{array}$ & $\begin{array}{r}8.38^{b} \pm 0.41 \\
46.67 \pm 2.71\end{array}$ & $\begin{array}{l}7.94^{\mathrm{ab}} \pm 0.32 \\
44.48 \pm 2.40\end{array}$ & $\begin{array}{l}8.21^{b} \pm 0.22 \\
44.66 \pm 3.09\end{array}$ & $\begin{array}{l}7.12^{a} \pm 0.21 \\
44.62 \pm 1.74\end{array}$ & $\begin{array}{c}0.024 \\
0.92\end{array}$ & $\begin{array}{c}0.85 \\
--\end{array}$ \\
\hline Calcium (\%) & $33.57^{b} \pm 0.20$ & $31.27^{a} \pm 0.55$ & $31.50^{a} \pm 0.45$ & $31.47^{a} \pm 0.83$ & 0.026 & 1.63 \\
\hline $\begin{array}{l}\text { Phosphorus (\%) } \\
\text { Leg weakness mortality }\end{array}$ & $11.86^{b} \pm 0.16$ & $10.38^{a} \pm 0.11$ & $10.68^{a} \pm 0.08$ & $10.39^{a} \pm 0.17$ & 0.000 & 0.40 \\
\hline $1^{\text {st }}$ week & 0 & 0 & 0 & 0 & -- & -- \\
\hline $2^{\text {nd }}$ week & 0 & $3(5.56)$ & $2(3.70)$ & $5(9.26)$ & -- & -- \\
\hline $3^{\text {rd }}$ week & 0 & $3(5.88)$ & 0 & 0 & -- & -- \\
\hline $4^{\text {th }}$ week & 0 & $1(2.08)$ & 0 & 0 & -- & -- \\
\hline $5^{\text {th }}$ week & 0 & $1(2.13)$ & $1(1.92)$ & 0 & -- & -- \\
\hline $6^{\text {th }}$ week & 0 & $1(2.17)$ & $2(3.92)$ & $2(4.08)$ & -- & -- \\
\hline $0-6$ weeks & 0 & 9 (16.67) & $5(9.26)$ & $7(12.96)$ & -- & -- \\
\hline Leg abnormality score & 1 & 5 & 5 & 5 & -- & -- \\
\hline
\end{tabular}

Each value is a mean of twelve observations. The values in parenthesis indicates the percentage of mortality.

Means with atleast one common superscript in a row do not differ significantly $(P>0.05)$. CD value at $5 \%$ level of significance.

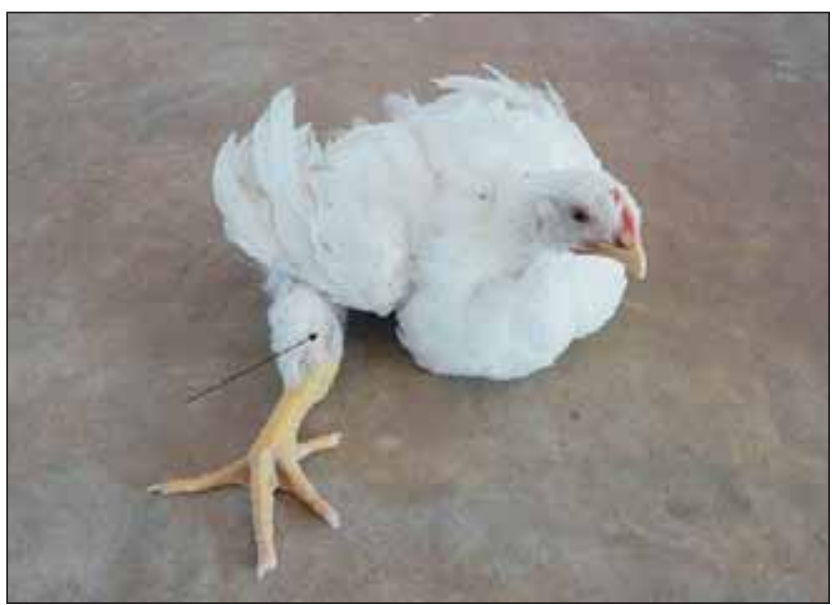

Figure-1: Slipped tendon causing leg weakness in high energy fed birds.

The tibial bone weight (g) and tibial bone ash (\%) were comparable among all the treatments; however, high energy groups had numerically low level of tibial bone weight. Defatted tibial bone weight of G4 was significantly lower than G1 and G3. Among the high energy groups the G3 have higher defatted weight which comparable to G1. The comparable bone weight, tibial bone ash and significantly low defatted tibial bone weight suggests that the organic matter in the bone of $40 \mathrm{mg} / \mathrm{kg}$ supplemented group might have been higher.

The tibial calcium and phosphorus (\%) levels were found to be lower in high energy fed groups than the G1. The reduced calcium and phosphorus per cent in the tibial bone might have been due to poor efficiency of absorption in these groups. Similarly, Venalainen et al. [10] reported that the tibia ash, calcium and phosphorus per cent in broilers were significantly lower in broilers fed high energy diet when compared to low energy. The decrease in serum and tibial calcium level might be due to the interaction of fatty acid with cations (calcium) resulting in the

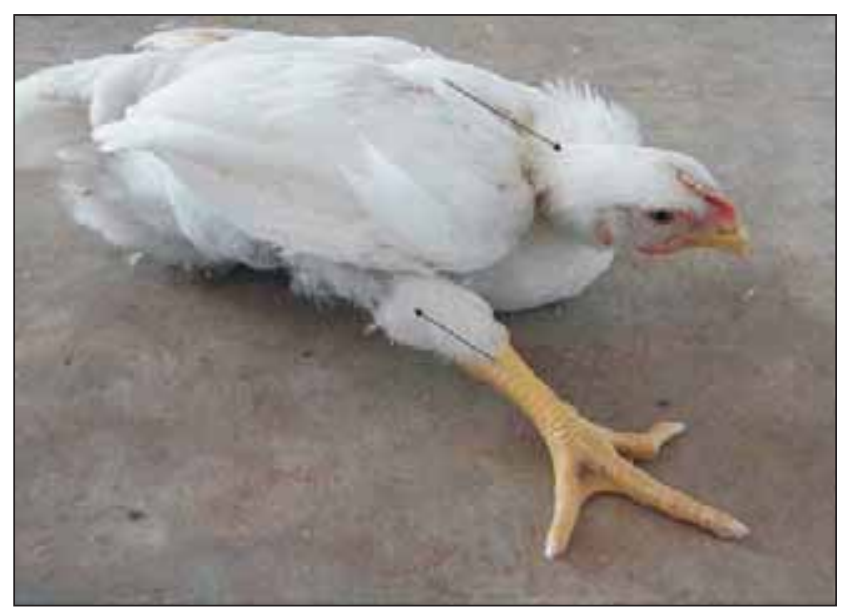

Figure-2: Rotation of tibio-tarsal joint in high energy fed birds.

formation of insoluble calcium soap and reduction in calcium absorption [18]. Mortality due to leg weakness was found to be higher in high energy diet when compared to normal energy and however, the mortality due to leg abnormalities in CoQ10 supplementation at both 20 and $40 \mathrm{mg} / \mathrm{kg}$ diet groups had lower mortality than the G2. The lower tibial calcium and phosphorus per cent in high energy diet would have resulted in higher incidence of leg weakness and hence the mortality. The leg abnormality score of high energy fed diets (both unsupplemented and supplemented groups) indicates more severity of leg abnormalities in high energy group (Figure-1 and 2). Metabolic utilization of these (mainly $\mathrm{Ca}$ and $\mathrm{P}$ ) nutrients can changed under heat exposure conditions in response to endocrine control [19].

\section{Conclusion}

Feeding of broiler with high energy diet under high environmental temperature reduces the serum and tibial calcium and phosphorus levels. The supplementation of CoQ10 did not alter the serum and 
tibial bone calcium and phosphorus levels. The leg abnormality associated mortality was significantly decreased in diets supplemented with CoQ10@20mg/ $\mathrm{kg}$ group when compared to the other two high energy groups.

\section{Authors' contributions}

MRP, DC were involved in the design of the experiment. MG carried out the broiler trial, data collection, analysis of data and prepared the first draft of the manuscript. MRP and DC assisted MG at all stages of the work. MRP and DC revised the manuscript. All authors read and approved the final manuscript.

\section{Acknowledgements}

The Authors are thankful to Dean, Veterinary College and Research Institute, Namakkal and Tamil Nadu Veterinary and Animal Sciences University for providing all the facilities and funds to carry out the present study.

\section{Competing interests}

The authors declare that they have no competing interests.

\section{References}

1. Onyango, E.M., Hester, P.Y., Stroshine, R. and Adeola, O. (2003) Bone densitometry as an indicator of percentage tibia ash in broiler chicks fed varying dietary calcium and phosphorus levels. Poult. Sci. 82:1787-1791.

2. Ciuchi, I.V., Olariu, C.S. and Mitoseriu, L. (2013) Determination of bone mineral volume fraction using impedance analysis and Bruggeman model. Mat. Sci. Eng. B. $30: 1-7$.

3. Blake, G.M. and Fogelman, I. (2002) Methods and clinical issues in bone densitometry and quantitative ultrasonometry. In Principles of Bone Biology, ed. Bilezikian, J.P., Raisz, L.G. and Rodan, G.A., San Diego: Academic Press, p15731585.

4. Sahin, K., Onderci, M., Sahin, N., Balci, T.A., Cikim, Sahin, $\mathrm{K}$. and Kucuk, O. (2007) The effect of soy isoflavones on egg quality and bone mineralisation during the late laying period of quail. Br. Poult. Sci. 48(3):363-369.

5. Post, J., Rebel, J.M.J. and Huurne, A.A.H.M.T. (2003) Physiological effects of elevated plasma corticosterone concentrations in broiler chickens. An alternative means by which to assess the physiological effects of stress. Poult. Sci.
82:1313-1318.

6. Belay, T. and Teeter, R.G. (1996) Effects of environmental temperature on broiler mineral balance partitioned into urinary and faecal loss. Br. Poult. Sci. 37:423-433.

7. Khattak, F.M., Acamovic, T., Sparks, N., Pasha, T. N., Joiya, M. H., Hayat, Z. and Ali, Z. (2012) Comparative efficiency of different supplements used to reduce heat stress in broilers. Pak. J. Zool. 44(1):31-41.

8. Vakili, R., Asghar, R.A. and Sobhanirad, S. (2010) Effects of dietary fat, vitamin $\mathrm{E}$ and zinc supplementation on tibia breaking strength in female broilers under heat stress. Afr. JAgr. Res., 5(23):3151-3156.

9. Julian, R.J. (1998) Rapid Growth Problems: Ascites and Skeletal Deformities in Broilers. Poult. Sci. 77:1773-1780.

10. Venalainen, E., Valaja, J. and Jalava, T. (2006) Effects of dietary metabolisable energy, calcium and phosphorus on bone mineralisation, leg weakness and performance $\mathrm{o}$ broiler chickens. Br. Poult. Sci. 47:301-310.

11. Papadimitriou, A., Hadjigeorgiou, G.M., Divari, R., Papagalanis, N., Comi, G. and Bresolin, N. (1996) The influence of Coenzyme Q10 on total serum calcium concentration in two patients with Kearns-Sayre Syndrome and hypoparathyroidism. Neuromuscul. Disord. 6(1): 49-53.

12. Nancy, E. and Broskie, M.D. (2013) Psychosis from coenzyme Q10 in two patients with low parathyroid hormone. Psychiatry Weekly, column. 8(17).

13. Lee, B.J., Huang, Y.C., Chen, S.J. and Lin, P.T. (2012) Coenzyme Q10 supplementation reduces oxidative stress and increases antioxidant enzyme activity in patients with coronary heart disease. Nutrition, 28(3):250-255

14. Tao, X. and Xin, H. (2003). Acute synergistic effects of air temperature, humidity and velocity on homeostasis of market-size broilers. Trans. ASAE, 46(2): 491-497.

15. A.O.A.C. (2012) Official Methods of Analysis Association of Official Analytical Chemists, $19^{\text {th }}$ Edn, Washington, D.C., USA.

16. Watson, L.T., Ammerman, C.B., Miller, S.M. and Harms, R.H. (1970) Biological assay of inorganic manganese for chicks. Poult. Sci. 49:1548-1554.

17. Riyazi, S.R., Vahdatpour, T., Mirzaei-Aghsaghali, A., Fathi, H., Davoodi, J. and Vahdatpour, S. (2011) The effect of energy increasing and protein lowering on performance and some serum biochemical parameters of broiler chickens. Ann. Biol. Res. 2 (4):516-521.

18. Gacs, G. and Barltrop, D. (1977) Significance of calciumsoap formation for calcium absorption in the rat. Gut. 18:6468.

19. Geraert, P.A., Padilha, J.C.F. and Guillaumin, S. (1996) Metabolic and endocrine changes induced by chronic heat exposure in broiler chickens: biological and endocrinological variables. Br. J. Nutr., 75:205-216. 